\title{
Observations on some Physical Properties of Protoplasm by Aid of Microdissection.'
}

\author{
BY \\ WILLIAM SEIFRIZ. \\ With one Figure in the Text.
}

INTRODUCTION.

F ARLY workers on protoplasm dealt entirely with living material. The advent of cytological technique with its methods of fixing and staining opened up a new and fertile field of investigation, leading to the discovery of many heretofore hidden structures of the cell. But it was soon realized that many of these structures were the direct result of the fixing and staining of the material. Consequently, there is to-day a pronounced reaction against this method of making observations and an increasing sentiment in favour of observations on living material.

\section{METHOD.}

Morphological work on living protoplasm has been greatly stimulated by the recent introduction of an ingenious technique generally known as the microdissection method. The instrument used in this method is a modification of the Barber (2) pipette-holder and consists of two mechanical needle-holders, each capable of being moved in three directions. Glass needles with very sharp and rigid tips are used for dissecting the material, which is suspended in a water film on the under side of a cover-glass that constitutes the cover of a small moist-chamber under the microscope objective. A complete account of the method and the technique connected with it is given in an article by Chambers (10), to which the reader is referred.

\section{Precautions.}

The student of living protoplasm soon learns to appreciate the necessity of knowing as far as possible the exact condition of the material which he is studying. Indeed, the great problem in microdissection is to know when one is observing living, and when dying or dead protoplasm. While the structure and behaviour of dead protoplasm is in many instances highly

${ }^{1}$ Botanical Contribution from the Johns Hopkins University, No. 68.

[Annals of Botany, Vol. XXXV. No. CXXXVIII. April, 1921.] 
instructive, yet they differ, often markedly, from the structure and behaviour of living protoplasm. However, where a structure cannot be readily seen in the living condition, but does, because of some physical or chemical change, become clear when dead, we are not, therefore, justified in utterly disregarding the evidence based on dead material. For example, the presence of a protoplasmic membrane in the living state cannot be indubitably established, yet the presence of the dead plasma-membrane is in some instances strikingly evident. As evidence for support of the existence of a living membrane, the presence of a dead membrane is not to be altogether ignored.

Not only must every precaution be exercised to avoid describing living protoplasm from observations on dead protoplasm, but one must also take care to ascertain if the substance under observation is true protoplasm or a modified form or a product of it, such as vacuolar sap or yolk, for example. Many plant cells are more than three-fourths sap with only a layer of protoplasm lining the cell-wall, and the volume of some fish eggs is nineteentwentieths yolk with but a thin coating of protoplasm enveloping the latter (before fertilization). In working on such material it is difficult to be certain that one is observing the behaviour of true protoplasm and not of sap or yolk. ${ }^{1}$

\section{TERMINOLOGY.}

While some writers condemn too precise a definition of a word it is nevertheless true that a very broad use of a term leaves open the possibility of a great number of interpretations, none of which may coincide with the specific one in the mind of the writer. The word 'membrane', because of its free and lax use, is an excellent example of the confusion which exists in biological nomenclature. The following are some of the expressions which have been used to refer to a single cell structure, namely; the plasma-membrane: 'phase boundary', 'surface film', 'surface layer', 'ectoplast', '(vacuole) wall', 'ectosarc', and 'hyaloplasm'. Where the jumble is one so hopeless as this, it is often convenient to use any one of the expressions in a purely abstract sense. This is what Stiles and Jörgensen have done. They $(41$, p. 533) have recently put in a 'plea for definiteness of statement and for the avoidance of semi-mystical expressions such as "permeability" or "plasma-membrane".' The plea for definiteness is a worthy one. But their solution of the difficulty which the many expressions for the protoplasmic membrane present, by using 'plasmamembrane' to mean 'that part of the cell which is concerned in the phenomenon of permeability without reference to its actual location in the cell' $(40, \mathrm{p} .50)$, is, perhaps, permissible where one has no interest in the plasmamembrane as such; it does not, however, solve the problem of the existence

1 Some other precautions in technique are given in a recent article on Viscosity values of Protoplasm (38). 
or non-existence of a plasma-membrane. To one concerned in establishing the possible morphological identity of a protoplasmic membrane there is but one course, namely, accurately to describe the thing and let this description stand as a definition for the name used.

\section{MATERIAL.}

The data upon which the following discussions are based were obtained by the study of a considerable variety of material. While the conclusions reached may be regarded as pretty generally applicable, it is to be understood that the statements made refer only to the organism under discussion at the time. Some of the physical properties of protoplasm are characteristic of all protoplasm, yet prominent dissimilarities do occur between even closely related species.

The following types are the chief ones used for this study: the myxomycetes Ceratiomyxa, Badhamia, Arcyria, Cribraria, and Fuligo; the ova of the rock-weed Fucus; the freshwater algae Spirogyra and Vaucheria; Elodea; the bread-moulds Rhizopus and Zygorhynchus; pollen tubes of the Blue Flag Iris versicolor, of the Beach-pea Lathyrus maritimus, and of the Dog's-tooth Violet Erythronium revolutum; the protozoa Amoeba and Euplotes; the ova of the sand-dollar Echinarachnius, of the sea-urchin Tripneustes esculentus, and of the silver (English) hake Merluccius.

The experimental work on these forms was done mostly in the Botanical Laboratory of the Johns Hopkins University. The work on marine forms, however, was carried on at the Harpswell Laboratory, South Harpswell, Me., and at Ocho Rios, Jamaica, B.W.I. ${ }^{2}$

\section{PROTOPLASMIC MEMBRANES.}

No topic in biophysics probably has been the subject of so much controversy as that of the plasma-membrane and its bearing on the phenomenon of permeability. Opinions upon it differ so widely that while its very existence is questioned by some workers, others positively assert that an actual morphologically and physiologically definite surface layer can be clearly demonstrated. Thus de Vries ardently supports its existence as a morphological entity, while Kite (23, p. 298) views it as a 'hypothetical' structure, and Fischer $(15$, p. 225) calls it a 'figment of the imagination'.

There are three main lines of attack on this problem, no one of which can by itself give conclusive evidence, although a combination of the

1 Other difficulties in nomenclature, especially in reference to such common colloid chemical expressions as 'gel', 'coagulum', \&c., are considered in the paper dealing with other physical properties of protoplasm already referred to (38).

${ }^{2}$ I am indebted to Director J. S. Kingsley for the use of a room at the Harpswell Laboratory. To Frank Cundall, Esq., I am greatly obliged for his kindness in placing the facilities of the Institute of Jamaica at my disposal. 
three does, it seems to me, give a very convincing if not irrefutable answer to the question. There is, first, the purely theoretical suggestion that some sort of membrane or septum is a physical necessity; that a membrane exists wherever two immiscible liquids come in contact. The retort to this contention is, that this is a question of definition, and that a surface tension membrane has nothing in common with osmotic membranes. A second method of attack on the problem is through the study of permeability. Most workers have concluded that a 'semi-permeable' membrane about a protoplast is a necessary prerequisite to differential permeability. The third mode of approach is through morphological data based on anatomical evidence of the presence of a definite structural membrane. It is with this third method that I shall deal.

If our discussion of the subject is to be at all intelligible it is necessary that we have a common understanding of the precise connotation of the word membrane. To the physicist a membrane is a solid structure, flexible in two directions and theoretically without thickness. A film, on the contrary, is a liquid structure, although even from physicists (34) do we hear of liquid membranes. Biological definitions of membranes run the whole gamut of physical possibilities, from a film two molecules thick to a tough parchment. Pfeffer, who is usually referred to as the chief advocate of the presence of a protoplasmic membrane, and who 'has shown remarkable ingenuity in the development of the plasma-membrane theory' $(23, \mathrm{p} .282)$, was not certain of the exact nature of the membrane. In fact, in justice to Pfeffer, it should be pointed out that he adopted the term plasma-membrane 'for the questionable surface layer of protoplasm' $(30$, p. 189) in order to have 'a precise designation for the diosmotic layer', but regarded the 'expression plasma-membrane as a makeshift' which he 'would gladly drop if a knowledge of the structure and quality of the hyaloplasm would permit it' (29, p. I 24). To Pfeffer, then, plasma-membrane was a convenient term for use in the consideration of permeability phenomena. It must be said, however, that Pfeffer in all probability believed in some sort of a definite protoplasmic membrane. ${ }^{1}$

Von Mohl $(26$, p. 93) was one of the first to suggest that the 'primordial utricle' was, perhaps, limited without by a special membrane lying next to the cell-wall. (It is interesting to note that von Mohl cautioned against regarding the plasma-membrane as a solid layer sharply differentiated from the inner protoplasm.) De Vries recognized not only an external membrane, to which he gave the name 'ectoplast', but also an inner protoplasmic membrane, which he termed 'tonoplast', surrounding each vacuole. Recent workers such as Vonwiller (44, p. 288) and Prenant (32, p. 94) recognize the presence of a membrane around all cell inclusions, such as the nucleus, the

1 'In every case the limiting membranes determine whether or not a given substance shall be absorbed ' (Pfeffer, 31, p. 92). 
vacuoles, and 'the bodies of every kind contained in the protoplasm'. The ultra-modern tendency is-and I quote from Berczeller's (5, p. 6I) work on the physical chemistry of membranes-' not to speak of "walls", "skins", or "membranes". We must not picture to ourselves a rigid layer, as the osmotic theory really demands but which has in animal cells never been observed; but we are dealing rather with liquid surface layers which in many cases . . . can also assume a solid form.' This reaction to the old notion of a plasma-membrane culminates in the school led by Fischer (15, p. I 58), who believes that 'There are no membranes about cells'. Indeed, so fearful have some become of giving credence to the existence of a true protoplasmic membrane that they are now quite satisfied with a layer of but two molecules in thickness to which to ascribe all permeability phenomena. ${ }^{1}$

Before discussing the experimental data which have led me to agree essentially with Berczeller in looking upon the plasma-membrane not as a skin, but as a highly viscous layer of modified protoplasm which may at times become quite fluid, it will be well to consider some membranes and surface layers which are pretty well recognized, chiefly with the view of excluding them from the discussion. ${ }^{2}$

Certain unicellular organisms are known to possess definite and readily isolated membranes; e.g. Vorticella has a tough membrane and Euplotes possesses a quite resistant pellicle. There is no contention over the existence of these structures. They may be said to be true membranes in the unqualified biological sense. There are, however, other unicellular organisms, such as Paramoecium bursaria and many species of $A$ moeba, which are generally considered 'naked'. (Some Amoebae are said to possess a membrane of appreciable thickness. Vonwiller, 44, p. 286.) In marine ova there may or may not be an easily recognizable membrane. In Fucus, e. g., there is an egg-wall measuring $\mathrm{I} \mu$ in thickness. In Asterias and Cerebratulus the eggs are surrounded by a membrane which, on fertilization (Asterias) or escape into sea-water (Cerebratulus), lifts off to form the fertilization membrane. In the Arbacia egg there is said to be no discernible membrane, therefore the fertilization membrane must be a precipitation product or a new secretion $(19$, p. 239$)$. These generally recognized and readily discernible membranes-'non-cellular secretions', which, in the zoological sense, are probably synonymous with the cell-wall of plants-are not the subject of the following discussion. We are concerned only with so-called 'naked' protoplasm, of which myxomycetes, most Amoebae, and all escaped protoplasm are examples. The same type of membrane which

1 Personally, I cannot believe that a two-molecule layer, i.e. a surface tension membrane, is sufficient for any differential permeability phenomena.

2 I prefer to keep the expression 'plasma-membrane' for the superficial layer of protoplasm. Little clarity will be gained by the substitution of any other name, old or new, until we have more real knowledge of the actual structure and composition of the plasma-membrane. 
delimits such 'naked' masses of protoplasm is also to be found as a covering of the cell protoplast lining the cellulose walls of plant cells.

Having eliminated the true and readily visible membranes (fertilization membranes, pellicles of certain Protozoa, \& $c_{\circ}$ ) as not closely comparable with the plasma-membrane, we may proceed further to discard one or two suggested conceptions of the protoplasmic membrane. Bütschli's alveolar layer has been referred to as a possible plasmatic membrane. I do not regard this as a correct interpretation. The alveolar layer is merely a palisade arrangement of the superficial alveoli. This arrangement can hardly give to the layer any decided special properties not possessed by the alveolar protoplasm within.

It has also been suggested that possibly the hyaloplasmic border of myxomycetes, and likewise the ectosarc of $A$ moeba, is the plasma-membrane, or, at least, functions as the differentially permeable layer. Pfeffer (29, p. I23) has advanced this possibility. This may hold true in permeability phenomena, where not only the hyaloplasmic layer but the entire living colloidal system may perhaps function osmotically, but, as I have reiterated, it is not with permeability that I am concerned. Microdissection evidence indicates the presence of a delicate layer of protoplasm external to and more or less distinct from the peripheral hyaloplasm.

Chambers apparently inclines towards the suggestion of Pfeffer that the ectoplasmic layer is the protoplasmic membrane, and does not definitely acknowledge the occurrence of a plasma-membrane such as I have just described, i. e. a delicate layer more or less distinct from the ectoplasmic border. Chambers's expressions for what might be construed as a plasmamembrane are 'surface film' and 'surface layer', and the latter he makes synonymous with ectoplasm $(8$, p. $4 ; 9$, p. I I). Only when the ectoplasm becomes an exceedingly thin layer, as in 'naked' marine ova, is it then even loosely comparable to a plasma-membrane. Chambers's 'surface layer' is not, even when thin, strictly a film or membrane (although he (11, p. 46) occasionally uses the word membrane), for he recognizes no line of demarcation between the surface layer and the inner plasm. The surface layer, as viewed by Chambers, is a region which 'merges insensibly' into the cell interior $(11$, p. 45$)$. Pfeffer expresses the possibility of this when he says that the more dense layer of the hyaloplasm is 'probably only an outer zone' (29, p. I23), and 'A definite delimitation of the plasmamembrane from the inner layers of hyaloplasm is not probable', unless a more thorough knowledge of the structure of the hyaloplasmic border should permit such an interpretation (29, p. I24).

With this knowledge of some of the many divergent conceptions of the plasma-membrane we are better prepared to interpret the following data:

The Living Nembrane. If the hyaloplasmic border of a plasmodium which is in the active stage-that is, if it is or has recently been streaming- 
and therefore is of low viscosity, is pierced by a microdissection needle and the needle is slowly moved toward the edge of the protoplasmic mass, the liquid hyaloplasm will follow the needle until a good-sized artificial pseudopodium is produced. The formation of so large a pseudopodium necessitates considerable increase in surface of the plasmodium in that region, to accomplish which the outer layer must either be in a liquid state or, if solid (i. e. a gel), must be capable of being greatly stretched. That the membrane is not elastic is readily determined when such a pseudopodium is being formed by releasing the needle and observing the absence of any appreciable contraction. The outer layer, therefore, must during pseudopodium formation, be in a liquid state. Increase in surface is accomplished by additions to the outer layer from the liquid hyaloplasm. There is no stretching in the sense of an elastic membrane, no great separation of the surface particles, but, as in any liquid film, with increase in area more particles are forced into the surface layer.

The experiment so far has proved only that the plasmodial surface is at pseudopodium formation liquid ; but that it differs from any other liquid surface has not been shown. Optically the liquid surface layer of a plasmodium is much more refractive in comparison to the interior protoplasm than is, for example, the liquid surface of water in comparison to its interior. In observing these liquid surfaces of streaming protoplasm one constantly gets the optical impression that the outer layer differs, and is sharply delimited from the bordering hyaloplasm.

The advance of such an artificially produced pseudopodium will at some point suddenly be halted by a change in consistency of the protoplasm, and this pronounced and sudden change takes place at the surface, for the inner hyaloplasm increases but little in viscosity. Subsequent advancement of the needle causes a break in the surface. The break is not sudden, however, for there is now some actual stretching of the firm (gelated) surface layer, which ultimately tears apart.

From these observations we may justly conclude that the surface layer of an advancing myxomycete pseudopodium is liquid, while that of an inactive one is firm. When a quiescent, and therefore more viscous, plasmodium is dissected in the manner above described there is no flow of protoplasm. The surface layer is, after some stretching, ruptured. We have here then a reversible solation-gelation phenomenon. The inactive surface layer is a highly viscous emulsion colloid, undoubtedly in the gel state, ${ }^{1}$ which solates (i. e. becomes a sol) when streaming takes place, and reverts to the gel state when the plasmodium again becomes inactive. This

1 The only criterion here for a gel or sol state is viscosity. This does not furnish conclusive evidence, but where the viscosity is so very high or so very low one can be reasonably certain that the protoplasm is, in colloidal structure, actually a gel in the first case, or a sol in the second case. (For a more complete discussion of this see 38 .) 
surface layer is exceedingly delicate, of immensurable thickness, and is not identical with the hyaloplasmic border (or ectoplasm), which, to be sure, it resembles in constitution, but from which it is more or less sharply delimited. ${ }^{1}$

The following extract from notes on my experiments shows how closely the behaviour of the surface layer of Amoeba resembles that of myxomycete plasmodia, and, like the latter, supports the theory of a delicate protoplasmic membrane.

- That portion of the membrane of new pseudopodia of Amoeba which is immediately concerned in the advancement of the pseudopodia - that is, the region of the membrane at the foremost tip of an advancing pseudopodiumis in a state of fluidity, while those regions of the membrane bordering the more or less quiet portions of the Amoeba are of very high consistency, undoubtedly a colloidal gel. The rapidity with which the liquid membrane of an advancing pseudopodium will gel is beautifully seen in the result of a rapid stretching of it. If the membrane of a quiescent $A$ moeba is torn it is found to have the consistency of a gel, and, though elastic, it tolerates only a moderate amount of stretching. On the other hand, the liquid membrane bounding the advancing part of a moving Amoeba behaves at first, if the dissection be quickly performed, exactly like the liquid membrane of a water droplet, but extension of the liquid membrane is possible for only a brief space of time, for gelation quickly takes place, after which the now gelled membrane may be stretched a bit, when it breaks.

The behaviour of the ectoplast is quite similar to that of the membrane, in this respect differing markedly from the hyaloplasmic border of myxomycetes. The ectoplasm of $A$ moeba is in a liquid state when actively flowing, but when quiet is of high consistency, though it never attains the rigidity of the passive membrane. It is this difference in density and consequent difference in degree of extensibility which makes it possible often to distinguish the membrane from the ectosarc even in the living condition.

The resistant, elastic, and highly viscous gel nature of the surface layer of $A m o e b a$ is evident from the following experiment. An active specimen of Amoeba was twice partially severed, leaving but a strand (apparently double) of protoplasm, the plasma-membrane, connecting the two halves. Subsequently, after the needles were removed, the two halves were drawn towards one another by contraction of the connecting elastic gel membrane, and on coming in contact they re-joined.'

1 De Bary's notion of the plasmodial membrane was also essentially this. He says (3, p. 42): - These facts ... do not permit it (the plasma-membrane) to be considered as a skin differentiated from the ground-substance, but it is to be looked upon as a special superficial layer of the living plasmodium, from which it is usually readily distinguishable.' 
These observations support the theory of amoeboid movement advocated by Hyman, who says $(21$, p. 88$)$ : 'Since the ectoplasm is a more or less rigid gel, the direct cause of pseudopod formation must be a local liquefaction, and the direct cause of the withdrawal and contraction of pseudopodia must be coagulation. This gelation and solation are the essential processes in amoeboid movement.' I believe, however, that it is probably primarily the membrane which functions in this solation-gelation phenomenon, since it becomes much firmer on gelling than does the ectoplasm.

A further bit of experimental evidence tending to show that the surface of protoplasm is far more viscous, resistant, and elastic than the interior, is to be had by tearing apart a mass of inactive and very viscous protoplasm. If two needles are placed within the highly viscous protoplasm of a myxomycete plasmodium and are then separated, the protoplasm will, as the limit of extensibility is approached, tear very much as bread-dough does when pulled apart, but there is almost invariably a remaining strand which persists for some time after the mass as a whole has separated. This remaining strand may be stretched to a very fine thread, exhibiting a surprisingly high extensibility. This persistent thread of protoplasm is always from the surface of the torn mass. If, now, the one needle is returned and again put into the protoplasmic mass near the ragged surface from which the membrane just described has been torn (the highly viscous and partly degenerate condition of the protoplasm prevents the formation of another membrane, i. e. the wound is not healed) and the two needles are again separated, the mass of protoplasm, when its limit of extensibility is reached, tears apart abruptly and cleanly. There is now no persistent outer layer of more viscous, resistant, and elastic protoplasm.

One of the fundamental properties of the living substance is the capacity instantly to surround itself with a membrane such as that which has just been described. Tears in the plasma-membrane are usually instantly repaired. When the surface of a plasmodium or of an Amoeba or an ovum is torn, it is, if the protoplasm is normal, immediately healed, and there is seldom any escape of protoplasm. This capacity exists even in the ova of Fucus, where the outer layer is not a membrane but a pliable wall of considerable thickness. A tear in this wall is rapidly repaired, the new covering being to all appearance identical with the old.

This capacity for forming protective membranes is to be observed in the behaviour of escaped masses of protoplasm. For example, ejected masses of protoplasm from pollen tubes sometimes develop membranes immediately on being freed. (The behaviour of escaped protoplasm from growing pollen tubes varies greatly. It is sometimes immiscible in the surrounding medium of water and immediately forms a membrane on being freed, while it equally often diffuses rapidly into the water with no indication of the formation of a membrane.) The membrane formed is surprisingly 


\section{Seifriz.-Observations on some Physical Properties of}

tough. Fragments of it can be dragged into the plasma mass. (This is, of course, the gelated, degenerate membrane. The living membrane cannot be separated from the protoplasmic mass.)

The highly viscous, inactive protoplasm from the hyphae of the bread-mould Rhizopus, when exposed by a rupture or when forcibly ejected through a tear in the filament of the mould, forms no membrane. Its high gel consistency is apparently not conducive to membrane formation. That protoplasm of gel consistency is incapable of forming a membrane is not surprising, since a not too high viscosity is a physical prerequisite to a readjustment of particles. On the other hand, very dilute protoplasm does not always form droplets, with apparent membranes, when freed. This truth is well illustrated in the behaviour of the protoplasm of Amoeba. The ectoplasm of $A$ moeba, though very viscous, will invariably, if normal, round up into small spheres when bits of it are isolated, while the endoplasm which is of low viscosity does not round up when freed nor form a protective surface, but mixes with the surrounding medium.

This behaviour suggests the view of de Vries that the plasmamembrane is formed only from the ectoplasm. De Vries looked upon the hyaloplasmic border of myxomycetes and Amoeba as the 'organ of cell membrane formation'. That the plasma-membrane is made from hyaloplasm (matrix) and not granular protoplasm is evident from the fact that it is hyaline and possesses no granules. That it is usually formed from the hyaloplasmic border of myxomycetes and the ectosarc of Amoeba is likewise very evident in view of the fact that these regions are external to the internal granular plasma and therefore are the first to come in contact with the surrounding medium when the surface is torn. But that the ectoplasm is the 'organ' of membrane formation is not without experimental disproof.

It is generally true that a rupture in the surface of Amoeba which leaves ectoplasm exposed is quickly covered over without much if any loss of protoplasm, and, further, small globules of ectoplasm pinched off readily round up and maintain their identity, although their viscosity is considerably higher than that of the endoplasm. The endoplasm, on the other hand, when exposed to the surrounding medium by a deep wound, usually flows out and mixes in the medium, and apparently never forms a protective membrane unless a surface layer of ectoplasm is first established. I have, however, observed so rapid a transformation of the freshly exposed surface of liquid endoplasm that granules are caught in the membranous gel. What usually takes place when an $A m o e b a$ is torn by a deep rupture and the liquid endoplasm is not lost by dispersion is, apparently, a rapid conversion of the peripheral granular plasma into a more viscous granule-free layer, the ectosarc, which, in turn, at its surface is converted into the highly viscous 
membrane. A deep tear in a myxomycete plasmodium will often result in the formation of globules of a hyaline substance with characteristic membranes, and these clear masses of substance are formed not from the peripheral hyaloplasm but from granule-free protoplasm which comes from the very centre of the plasmodium. Thus, it is apparently the hyaline matrix, whether peripheral in location or not, which is capable of forming a membrane in myxomycetes. (Whether or not the peripheral hyaloplasm of myxomycetes is identical with the matrix of the granular plasma, differing only in location, cannot be said, but the two are not as highly differentiated as are the ectoplasm and endoplasm of Amoeba. In the ciliate Euplotes the differentiation between the two regions is still greater.)

The capacity for membrane formation persists only as long as the protoplasm is normal (although this property of membrane formation is one of the last to be lost in dying protoplasm). This fact is well illustrated in the behaviour of escaping protoplasm, from a bread-mould hypha or a filament of Vaucheria, for example. The first protoplasm which streams from a rupture almost invariably forms protective membranes (unless the escaping protoplasm be of very high viscosity, as is true of the quiescent protoplasm in Rhizopus). These liquid membranes at first readily increase in area as the droplet of escaping protoplasm increases in volume, but later they suddenly gelate and rupture from pressure of the inflowing protoplasm. The physiological change which has caused the gelation of the membrane surrounding the freed protoplasm had also robbed the now degenerate escaping protoplasm of the capacity to form a membrane.

The evidence so far presented favours the belief in a protoplasmic surface layer which is usually in the gel state (i. e. firm in consistency). This is also Chambers's contention (11, p. 45). But to Chambers the surface layer of so-called 'naked' protoplasm is frequently of ' an appreciable depth '-that is, the degree of viscosity (of the protoplasmic surface layer) is greatest on the outer surface and least on the inner surface. Thus does the high consistency at the surface grade insensibly into the very fluid condition of the interior. When the surface layer is sub-microscopic, such as may form over protoplasm which has freshly come in contact with water, then Chambers's surface film is identical with the protoplasmic membrane as I have described it. But when Chambers regards the ectosarc of Amoeba, which may attain a thickness of 10 or more micra, as the plasma-membrane, I cannot agree with him. On the contrary, I believe that the hyaloplasmic border of myxomycetes, the ectosarc of Amoeba, and the surface of all so-called 'naked' protoplasm is possessed of an ordinarily highly viscous outer protoplasmic layer of such delicacy as to be immensurable, but which does not necessarily grade imperceptibly into the more liquid condition of the interior. This outer layer is sometimes so definitely delimited from the inner protoplasm as to be optically distinguishable as a definite membrane. 
Though this is with difficulty seen in the living condition, it is often readily to be seen in degenerate protoplasm. ${ }^{1}$

The Degenerate Membrane. The observations so far presented have had to do almost entirely with the living plasma-membrane. Although the evidence for the presence of an outer more viscous protoplasmic layer seems to me to be conclusive, it must be admitted that this layer cannot be irrefutably demonstrated to be, in the living state, a definite membrane quite distinct from the protoplasmic mass which it bounds. The structure is such a delicate one, and is, after all, so little different from the inner protoplasm itself (of which it is when liquid so intimate a part), that separation of the living membrane by dissection is a physical impossibility.

The reactionary attitude of our science to observations on dead material is a healthy one. The criticisms directed against any evidence which purports to prove the existence of a living membrane by the presence of a dead one are legitimate. For example, the dead structure may be an entirely new product-perhaps a precipitation is formed as a result of death. That this is a possibility, I grant. But the dead membrane is to all appearances so evidently a structure having the same position and dimensions as that which can sometimes be observed on living protoplasm, that it is worthy of some consideration as evidence of the existence of a membrane about the living substance.

If the escaped protoplasm from a pollen tube, of Iris e.g., is allowed to gel-that is, to degenerate-the membrane formed at the time of ejection becomes fixed (possibly coagulates). It can then sometimes be isolated from the protoplasmic mass and dragged about as one would handle a film of scum such as forms on boiled milk.

In a myxomycete plasmodium one frequently finds large globular masses that are quite distinct from the larger protoplasmic mass in which they rest. The protoplasm which they contain is, so far as can be determined, identical with that of the plasmodium proper. These globules can be isolated and torn open, and when partly emptied they are found to be sacs bounded by a delicate membrane which on dissection is found to be a tough rigid gel. Before isolation, when the globule is handled while still within the plasmodium, the membrane is soft and exceedingly sensitive, often breaking before a perceptible indentation can be made. The change from this state to that of the isolated membrane is the result of degeneration and gelation.

1 Sharp delimitations between protoplasmic regions are common enough in organisms. That such structures as the nucleus, chromatophores, \&c., are sharply delimited from the surrounding protoplasm is evident, but even less specialized regions such as the ectoplasm may be sharply delimited from the rest of the protoplasm. Of the ectoplasm of Euplotes, Taylor (42) says, 'Frequently, there is evident a fairly definite boundary between the ectoplasm and endoplasm, but this condition apparently varies. If (upon disintegration) its outflow be not too rapid, the endoplasm separates from the ectoplasm ...' 
The membranes so far discussed have been those on 'naked' masses of protoplasm, such as myxomycetes and Amoebae and escaped protoplasm. It has long been believed that protoplasm within a cellulose wall is bounded by a membrane which by Pfeffer and others has been looked upon as the osmotically functioning region of the plant cell.

This outer protoplasmic layer next to the cellulose wall de Vries termed the ectoplast. Direct evidence of its presence in the living condition is very difficult to obtain. I have, however, observed it after degeneration and consequent coagulation have made it coherent and rigid enough to be separated from the protoplasm.

The hyphae of the bread-mould Rhizopus are frequently very turgid. Occasionally a filament can be found in which the protoplasm is a firm jelly and is sufficiently turgid to cause a slight protrusion of the protoplasm from the hypha when this is ruptured. By pressure with a needle some distance behind the torn end, the rod of protoplasm can be made to ooze out like oil paint from an artist's tube. This protoplasmic jelly is sufficiently rigid to hold its shape until dissected. It remains immiscible in the watery medium. Dissection will sometimes reveal, next to the protoplasmic rod, a delicate membrane which on further dissection proves to be a thin outer layer of highly viscous, gelled protoplasm enveloping the rod, and far more rigid and resistant than the soft protoplasmic jelly within. This thin membrane may be partially freed from the rod of protoplasm. I know of no other satisfactory designation of this firm outer layer than that it is the ectoplast, the plasma-membrane (in a degenerate, gelated state).

The Vacuolar Membrane. I have referred to the difference in behaviour of freed protoplasm from pollen tubes. Frequently, the protoplasm mixes with the surrounding water immediately on escaping. If the larger vacuoles thus set free by the escaping protoplasm of a germinating pollen grain are observed, they will be seen to be surrounded by a thin but plainly visible protoplasmic membrane. Clinging granules can be seen to glide along its surface. This membrane permits the vacuole to maintain its identity for several seconds while free in water. The volume of the vacuole slowly increases, due to osmosis, until it becomes twice its original size, when it bursts.

The vacuolar membrane may, when exposed to water, undergo a decided change. The many small vacuoles ejected with the liquid protoplasm from a hypha of the bread-mould Rhizopus are found, when exposed to water, to possess a quite resistant membrane which tolerates considerable pressure. But when these vacuoles are handled while still within the mass of protoplasm they burst at the slightest touch.

This view of the vacuolar membrane as a somewhat differentiated layer of protoplasm closely comparable with the external plasma-membrane 
rather precludes looking upon the vacuole as an autonomous or permanent organ. ${ }^{1}$

The behaviour of the contractile vacuole of certain Protozoa, as apparently first described by Wrześniowski (45 and 46), to which my attention was called by Dr. C. V. Taylor, who has observed the same temporary existence of the contractile vacuoles in Euplotes and Paramoecium, quite does away with the possibility of looking upon the contractile vacuole of Protozoa as a permanent organ, and therefore precludes the existence of any sort of permanent protoplasmic membrane surrounding the vacuole. It seems $(45, \text { p. } 162)^{2}$ that the contractile vacuole in certain Protozoa is formed by the fusion of several smaller vacuoles, and on ejection of the vacuolar contents to the exterior, a new vacuole is formed by the fusion also of several smaller ones, and the formation of the new vacuole may bein fact, usually is-initiated before the complete disappearance of the old discharging vacuole.

The fusion of the vacuoles and the temporary life of the ultimate contractile vacuole make it difficult to conceive of the vacuole as so intricate an apparatus as Stempell (39, p. 458) describes it. But especially does the fusion of the vacuoles indicate the temporary and facile character of the 'wall'. If the vacuolar membrane is at any time a rigid gel, solation apparently takes place on the fusion of two vacuoles and also on contraction of the ultimate vacuole.

Thus is the vacuolar membrane, like the peripheral cytoplasmic membrane, essentially protoplasm, fluid in consistency, and if at times it is in the gel state then it is readily reversible.

The Nuclear Membrane. The most beautiful demonstration of a protoplasmic membrane (using protoplasm in its broadest sense) is to be had by dissecting the isolated nucleus of an Amoeba. The nuclear membrane is generally believed to be a more definite and more readily distinguishable structure than the surface membrane of cytoplasm. This may be true, but the nuclear membrane cannot in the living state be any more readily distinguished or isolated than can the outer cytoplasmic membrane.

Kite $(22$, p. 6) describes the nuclear membrane of the eggs of Asterias, Cuminga, \&c., in these words: "This structure is a concentrated tough gel of relatively high viscosity and is not to be confused with the hypothetical surface of vacuolar plasmatic membranes.' Chambers $(9$, p. 10) supports Kite with the statement: 'Evidence that this membrane is a morphological structure is shown on withdrawing some of the nuclear contents with a micropipette.

1 Arthur (1, p. 499), in describing 'the variety of catastrophes which overtake the moving vacuoles' in the hyphae of bread-mould, says, 'I cannot see... any ground of support for the supposed autonomy of the vacuoles and a special vacuolar membrane advocated by de Vries, Went, Wakker, Bokormy, and others.'

2 This résumé was taken from the article in Russian by Wrześniowski (45), but reference is also given (46) to the more extensive work in German. 
The nucleus then partially collapses, throwing the nuclear surface into irregular folds.' This is, of course, only evidence of the fact that the nuclear membrane, like the plasma-membrane, may at times exist in the gel state, although here I doubt very much if a nucleus subjected to such treatment would long remain normal. The folded nuclear surface may be coagulated.

Whether or not we are justified in calling the nuclear membrane a morphological structure, any-more than that expression is applicable to the cytoplasmic membrane, is doubtful. Chambers $(9, \mathrm{p}$. Io) describes an experiment in which he cut the nucleus of an ovum in two. Each part
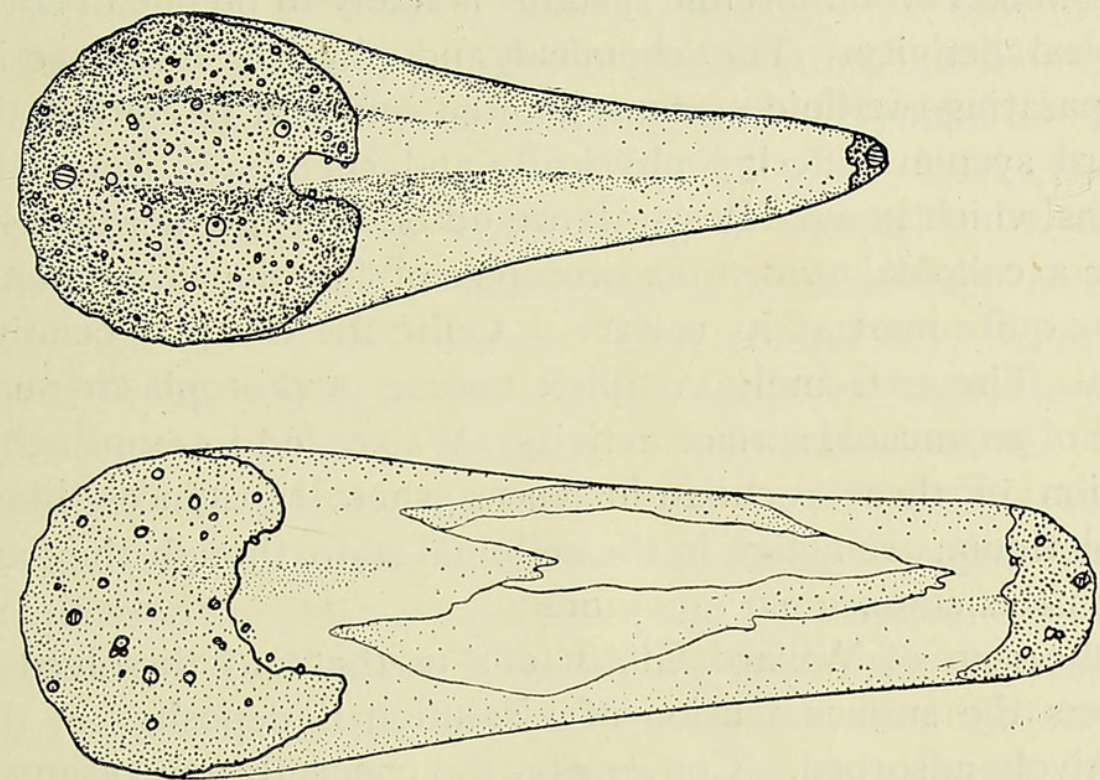

The isolated, degenesate Amoeba nucleus from which the coagulated nuclear membrane has been partially separated.

rounded up into a droplet. On coming in contact the droplets ran together. This observation restricts our notion of a morphological structure as applied to fluid membranes. ${ }^{1}$

The accompanying figure illustrates how nicely the nuclear membrane can be torn off after isolation, and hence after degeneration of the Amoeba nucleus. Staining with methyl blue intensifies the delicate membrane. The nuclear substance after isolation degenerates into a coagulum into which the microdissection needles are placed. As the needles are separated the nuclear membrane tears off as a thin though quite resistant veil.

Physical Chemical Evidence bearing on the Existence of a Plasma-

1 Botanical cytologists, working on fixed and stained material, have viewed the nuclear membrane as a very definite and readily distinguishable structure (when dead). Mottier (27, p. I9I) describes how the nuclear membrane of pollen mother-cells of Lilium appears to be made from the fibrillar kinoplasm, and Yamanouchi $(47$, p. $43 \mathrm{I})$ describes how ' the membrane of the original nucleus in the tetraspore mother-cell (of the red seaweed Polysiphonia) persists through the two mitoses'. 
membrane. The colloidal nature of the plasma-membrane, its structure and composition, how it is formed, and how it functions are all problems of great interest, but they are chiefly problems of colloidal and molecular physics, and therefore primarily of so theoretical a nature that few irrefutable statements can be made regarding them. However, the physical chemical evidencebearing on the existence of a plasma-membrane is of so fundamental, even though theoretical, a nature that it deserves very careful consideration.

From familiar surface tension phenomena we know that the surface of a liquid is the seat of certain physical forces which give to the surface layer a structure differing from that of the interior. Furthermore, all chemical reactions are surface ones ; consequently, we can conclude that the region of contact between two immiscible systems is likely to be one of both physical and chemical activity. The chemical and physical forces active in the septum separating two fluid systems is often sufficient to convert the septum into a third system differing physically and chemically from either of the two systems which it separates. It would be very extraordinary indeed if so intricate a colloidal system as protoplasm should prove an exception to this and be quite inert at its surface. Quite the contrary condition is the likely one. The extremely complex nature of protoplasm suggests the occurrence of an unusual surface activity. We are led to expect this through consideration of those peculiar instances where substances, like colloidal (spongy) platinum, are active in the colloidal state, though they are inactive when not in this state.

The theorem of Willard Gibbs tells us that any dissolved substance which lowers the surface tension of a solution is deposited at the surface, i. e. is positively adsorbed. Conversely, the concentration of any substance which raises the surface tension is less at the surface. Such selective adsorption results in the production of a region which, without any actual chemical reaction, differs in chemical make-up from either of the two original systems. But adsorption is always a preliminary to chemical action (although chemical union need not always follow adsorption. Whether adsorption is purely a physical union or a chemical one is simply a question of degree of firmness of the bond. A loose chemical union and a firm physical one are in this respect the same). Consequently, there cccur in the region of separation chemical activities peculiar to the septum alone, which, in turn, produce substances foreign to either of the systems which the septum separates. Just how far this process goes in the formation of the plasma-membrane cannot be said. But, realizing the possibilities which so complex a colloidal system as protoplasm offers to physical and chemical surface activity, there is every justification for assuming, $a$ priori, that the septum which separates protoplasm from its surrounding medium is itself a system differing in chemical composition as well as in physical structure from both of the systems which it separates. 
I have spoken only of surface forces. That these are sufficient to satisfy all membrane activity is unlikely. The state of equilibrium which is established in the membrane, and to perhaps a less degree in the hyaloplasmic border, is upset by extension and contraction. What forces are concerned in re-establishing this equilibrium we can only conjecture. But in considering them one must not lose sight of the fact that the organism is full of regulatory reactions, and an explanation of membrane formation based simply on surface phenomena is undoubtedly inadequate.

Comparison of the Plasma-membrane with Precipitation Membranes. Just how closely the plasma-membrane is to be compared with those precipitation membranes which are formed when two substances such as $\mathrm{CaCl}_{2}$ and $\mathrm{K}_{2} \mathrm{CO}_{3}$, or $\mathrm{CuSO}_{4}$ and $\mathrm{K}_{4} \mathrm{Fe}(\mathrm{CN})_{6}$ are brought together is a matter open to discussion. These precipitation membranes and the plasma-membrane have much in common, but also differ in some very fundamental properties. (I am adverse to making any distinction between the living and the non-living which tends to ascribe to the living any properties not possessed by the non-living, other than such as result from the great complexity of the former. This complexity, or organization as it is sometimes called, is, however, a distinguishing characteristic of the living, and we have as yet no satisfactory explanation of it. The living membrane manifests this organization-that is, it exhibits certain selfregulatory reactions not possessed by the non-living membrane.)

Comparison of the plasma-membrane and the classical Traube precipitation membrane of $\mathrm{Cu}_{2} \mathrm{Fe}(\mathrm{CN})_{6}$ is misleading in at least one respect. The former is a reversible gel, ${ }^{1}$ the latter an irreversible one; the former grows by reversion to a sol and the addition to the surface of colloidal particles from the interior; the latter (the Traube membrane) grows by rupture of the surface and the formation of a new membrane. Höber (20, p. 64) says, 'The plasma-membrane must probably be a thin surface layer comparable to a Traube precipitation membrane'. This may be true in a very broad and general way, but Höber's further statement, that as the Traube membrane grows so does the plasma-membrane, is not true if the comparison is to the method of growth by rupture and subsequent healing which is characteristic of the typical Traube membrane. Growth of the plasmamembrane is accomplished by a deposition of colloidal particles (and possibly substances in molecular dispersion) at the surface between the particles already at the surface which become somewhat separated as the area of the fluid membrane increases. (The deficit of colloidal particles just below the surface, which results from this surface deposition, is replenished from within by diffusion.) A better analogy is to be had in the remarkable precipitation membrane produced by bringing $\mathrm{HCl}$ and

1 Bechhold's statement (4, p. 56), 'We may describe membranes as irreversible gels', if in reference to living plasma-membranes, is quite untenable. 
$\mathrm{Na}_{2} \mathrm{SiO}_{3}$ together $(35$, p. 68I). This membrane may remain liquid for months. The duration of liquidity of most of these precipitation membranes ranges from 3 to I 20 seconds. Quincke (36, p. 722) describes these membranes as 'a very thin invisible film of an oily liquid precipitate'. In these physical, as well as in some of their osmotic properties, these precipitation membranes are very similar to the plasma-membrane. Whether or not the protoplasmic membrane is a precipitation membrane, one cannot say definitely. I am inclined to believe that it is not, primarily because of its ready reversibility.

Thickness of the Plasma-membrane. As yet no mention has been made of the thickness of the plasma-membrane except to say that it is very delicate. Any attempt to estimate its thickness (after it is isolated and has coagulated) with the aid of a micrometer, the very graduating lines of which exceed in breadth the apparent thickness of the membrane, will, of course, be very crude. Yet I made such attempts and estimated the thickness to be less than one-fifth of a micron. This value is not far from that given by Quincke for the thickness of some of the precipitation membranes with which he worked. He says $(34$, p. 630), "The thickness of this oil layer can, according to my investigation, be so small, less than $0.031 \mu$, that it can no longer be perceived with our best microscopes'.1

Dewar $(13$, p. 16), working on soap films, gives the far more minute thickness of soap bubbles 'thinned to the "black" stage' (this closely approaches the minimum thickness of such films) as ' I $5 \mu \mu$ 's.' Bechhold $(4$, p. 34), in reporting the work of others, also gives a very low figure. To quote: "The thickness of the layer which will just form a solid skin has been measured, and found to be, for peptone $3 \mu \mu$ (Metcalf), for albumin 3 to $7 \mu \mu$ (Devaux). Thus it is probably many times greater than the hypothetical diameter of a molecule, perhaps even equalling the radius of molecular attraction.' That the value may not only equal but exceed the radius of molecular attraction is suggested by Quincke $(35, \mathrm{p} .63 \mathrm{I})$, who states that,

1 I should like to call attention to some statements on the limit of size of objects visible and measurable with the modern microscope. Czapek (12, p. 25) states that 'Ordinary microscopical observation with the strongest lenses can show particles of about $25^{\circ} \mu \mu$ in diameter'. One quarter of a micron $(25 \circ \mu \mu)$ is not only not the limit of visibility of the strongest lenses, but is actually within the limit of fairly accurate mensurability. Quincke (34, p. 630) remarks, as quoted above, that the thickness of a precipitation membrane is less than $0 . \mathrm{I} \mu$, which cannot be perceived by the best microscopes. I cannot agree with either Quincke or Czapek, although Quincke's statement is much nearer what I find to be true, namely, that the limit of visibility is about, but probably somewhat less than, $0.000 \mathrm{Imm}$. $(0 . \mathrm{I} \mu)$. The value given by Taylor $\left(43, \mathrm{p} .4^{2}\right)$ is somewhat above this. He says, 'A sol whose particles are less than about $0.15 \mu$ will not be recognizable even with the best microscope (magnification 2,250)'. An extremely low value is given by Burton (6, p. II 7 ) in a table of 'Lower limits of diameters of small particles'. He gives the size of a particle visible under the 'ordinary microscope' as $2.5 \times 10^{-6} \mathrm{~cm}$. $(0.25 \mu \mu$ is also given, but this is undoubtedly a typographical error, since $25.0 \mu \mu$ and not $0.25 \mu \mu$ equals $2.5 \times 10^{-5} \mathrm{~cm}$.). This value in nicra is $0.025 \mu$. Possibly Czapek had this figure in mind when he gave $250 \mu \mu$ as the limit, but misplaced the decimal point. We may safely conclude, then, that the limit of microscopical visibility is not above $0.1 \mu$. 
'This border value (i.e. the thickness of the membrane upon which certain surface-tension values depend) is just twice the effective radius of molecular forces...' These suggestive values are mere analogies, but there is good reason to suppose, because of the similarity in physical properties and method of formation, and of actual, albeit rather crude, estimation, that the thickness of the plasma-membrane is of the order of magnitude of precipitation membranes, namely $0.000 \mathrm{I} \mathrm{mm}$. (0.1 $\mu$ ).

It is of value as well as of interest to consider the findings of physicists who step temporarily into the field of biology to work upon living material in order to compare the phenomena observed there with similar phenomena seen in the inorganic world. Quincke $(34$, p. 629), in working upon the cells of Chara, Elodea, \&c., found that the two masses of protoplasm which have become separated as a result of plasmolysis of a cell do not always unite on coming together when the protoplasm swells, but are separated by a film similar to that which surrounds the entire protoplast. Comparing the physical properties of this film with those of solid and liquid lamellae of inorganic precipitates, Quincke concludes that this protoplasmic film is 'a very thin liquid membrane'. Lehmann (24, p. 409) also believes that the comparison of the liquid membranes of artificial cells with the living plasmamembrane is of more than merely superficial significance.

Attempts on my part to establish the presence of a plasma-membrane through observation with the ultra-microscope were unsuccessful. Though it was possible to observe the vibration of colloidal particles in the hyaline matrix of myxomycetes, there was no distinct outer layer discernible by aid of dark ground illumination. ${ }^{1}$

\section{SUMMARY.}

I. The direct evidence from microdissection indicates the existence of a plasma-membrane on the surface of all protoplasm.

2. The indirect evidence derived from a consideration of surface phenomena strongly supports the belief in a differentiated surface layer of protoplasm.

3. The plasma-membrane is essentially protoplasm, although it differs in physical properties, and probably also in chemical constitution, from the mass of plasma which it bounds.

1 Gaidukov $(16, \mathrm{p} .50)$, in connexion with his observations on botanical material by means of the ultra-microscope, says, 'The cell membrane exhibits a pronounced optical inhomogeneity, which does not interfere with the investigation of the cell contents'. The last clause of this sentence makes one wonder if Gaidukov actually has reference to the plasma-membrane. The German word 'Zellmembran' is synonymous with 'Zellhant', which is the 'Plasmahant' or plasma-membrane. It is unfortunate that he does not describe his observations in greater detail if he was actually able to distinguish the protoplasmic membrane by aid of dark-ground illumination. $\mathrm{He}(\mathbf{1 6}, \mathrm{p} .74)$ does, however, say, 'The hydrosol complex of protoplasm (cytoplasm) is protected by a hydrogel layer (plasma-skin) ...' 
4. The plasma-membrane is commonly of high viscosity, undoubtedly a gel, but it readily reverts to the liquid sol state.

5. The plasma-membrane is, above all, facile. It is capable of ready adjustment to changes in contour and area.

6. One of the characteristic properties of the living substance is the capacity to form, almost instantly, a membrane on its surface. The few apparent exceptions to this have to do with protoplasm of extreme liquidity.

7. The living membrane, though rather sharply delimited from the inner plasm, is not capable of isolation.

8. The degenerate, coagulated plasma-membrane can sometimes be isolated. It is then seen to be of very firm consistency, elastic, and exceedingly tough.

9. The nucleus and vacuoles also possess protoplasmic membranes which are closely similar to the outer plasma-membrane.

10. The thickness of the plasma-membrane is probably about O.I $\mu$.

\section{THE NON-MISCIBILITY OF PROTOPLASM IN WATER.}

If we accept a simple, non-technical definition of the term miscibility we may then proceed with satisfaction to a discussion of the problem of the miscibility of protoplasm in water. If, however, we try to base our definition on the molecular physics of the phenomenon we are likely to get into difficulty, because our problem will become so involved with the physics of diffusion and imbibition that the original simple question, Is protoplasm miscible in water? will be completely obscured in a theoretical discussion. In order, however, to arrive at a definition of miscibility which will avoid danger of confusing the latter with the closely related phenomenon of imbibition it will be necessary to discover to what extent one is justified in distinguishing between the two phenomena.

When a dry reversible gel, such as glue, is wetted, there is first a pronounced swelling, but the individuality of the original piece of glue is not lost. The piece has merely increased in volume. So far, only imbibition, i.e. absorption of water and consequent swelling, has taken place. But as absorption increases the original glue mass begins to disintegrate, and ultimately we have an aqueous dispersion (colloidal solution) of glue. Imbibition has given way to diffusion, and the merging of the one phenomenon into the other was gradual and imperceptible. In the last analysis the molecular physics may be the same in both cases, the distinction between the two phenomena being merely one of degree.

It is quite possible that the behaviour of protoplasm in relation to water is closely analogous to that of glue, and we are thus put to it to decide whether the taking up of water by protoplasm is to be regarded as 
a process of diffusion or one of imbibition. Consequently, if we define miscibility as capability of diffusion, a solution of the problem of the miscibility of protoplasm in water resolves itself into the problem just stated, namely, Is the taking up of water by protoplasm a phenomenon of diffusion or one of imbibition? Should we decide that it is an imbibition process, are we then justified in look ing upon protoplasm as water-miscible? The former question is not readily nor irrefutably answerable. As for the latter, I think that we are quite justified in saying that miscibility and imbibition are not, in certain important respects at least, identical. It would be carrying our interpretation to the point of absurdity to grant, e. g., that a blotter or a sponge is miscible in water.

The question, Is protoplasm miscible in water? is, then, best considered first in its simplest form, taking a dictionary definition of miscibility. If miscibility means capability of mixing, does protoplasm mix with water when the two are brought together?

To begin with, we know of certain so-called 'naked' masses of protoplasm, such as Amoeba and myxomycete plasmodia, which live in water. Self-preservation of the organism, therefore, would demand that this protoplasm be immiscible in water. But we are told that these masses possess an outer layer which protects the protoplasm. To this one can justly reply that the outer layer is itself protoplasm, differing somewhat from the inner protoplasm, to be sure, but essentially protoplasm. (If, of course, the plasma-membrane is a typical precipitation membrane, and therefore an entirely new product, which, however, I do not believe to be the case, then the above reply is not valid. Chambers, who supports the view that protoplasm is miscible in water, must, since he makes surface layer synonymous with ectoplasm (8, p. 4), admit that this surface is essentially protoplasm. What Fischer holds regarding the nature of the outer surface of protoplasm I cannot say. He (15, p. I $\left.5^{8}\right)$ does not, however, look upon it as a membrane. Without further qualification this hypothesis of the absence of membranes about cells precludes the miscibility of protoplasm.) But if there is some objection to looking upon this outer layer as protoplasm, or if it is said that its immiscibility is not proof of the immiscibility of the inner protoplasm, we can carry our investigation farther and tear open some cells and see what happens when a fresh surface of protoplasm is exposed to water. This simple and direct method of deciding such a problem was the one employed by the pioneer workers on protoplasm, who were not greatly influenced by theories in molecular physics and colloid chemistry. The keenly analytical observations of early investigators, because of the simple and direct methods employed, are, it seems to me, of more than historical interest.

The first mention of 'sarcode', the original zoological name for protoplasm, is in Dujardin's 'Recherches sur les Organismes inférieurs' (I835). 
He there $\left(14\right.$, p. $\left.3^{6} 7\right)$ describes the 'living jelly' as a 'transparent, glutinous substance, insoluble in water' ("cette substance glutineuse, diaphane, insoluble dans l'eau'), and further (14, p. $\left.3^{68}\right)$ emphasizes 'its insolubility in water' as one of the properties which distinguish it from 'substances with which it might be confounded', such as 'albumin, which it resembles in its mode of coagulation'. But one does not have to go back nearly a century for authoritative evidence on the immiscibility of protoplasm. Hertwig $(19$, p. I 3$)$ speaks of protoplasm as a 'viscous, almost always colourless, in water-immiscible substance', and Bütschli $(7$, p. 543$)$ says, 'Since the fact exists ... that protoplasm is not miscible in water...' These statements are probably the outcome of direct observations on the behaviour of protoplasm in water. Such observations can be readily made by aid of microdissection.

If an ovum of the sea-weed Fucus or of an echinoderm is torn by microdissection needles, one of three things will happen : the egg will most often heal the wound with little or no loss of protoplasm; occasionally it will burst at the first touch of the needle and the egg contents scatter with the violence of a miniature explosion $\left(37\right.$, p. $\left.3^{16}\right)$; rarely will the protoplasm flow out and mix with the surrounding water. In the last two cases the escaped cell content is miscible, but it is then no longer real living protoplasm, for those peculiar properties which make protoplasm a living substance are lost. If the tear is so large that much of the protoplasm escapes, this escaping protoplasm will usually round up into droplets with no indication of mixing with the water. The dissection of many dozens of marine ova supports this statement. To cite but one instance-the dissection of some twenty eggs of the sea-urchin Tripneustes resulted in two cases of rapid miscibility, and these were both of eggs which showed other signs of degeneration such as previous excessive imbibition. The rate and percentage of spoiling among marine ova is rather great. These degenerate eggs go to pieces readily. Frequently, a healthy egg will exhibit great resistance and tolerate a surprising amount of dissection. For example, one Tripneustes ovum withstood several minutes of dissection, during which time the protoplasm was kneaded, torn, and droplets of it pinched off. There was no indication of miscibility until apparently the 'organization' of the protoplasm finally completely broke down, and general disintegration set in, with, of course, loss of individuality of the cell-that is, of those properties which make of the cell an organized living unit.

The same behaviour characterizes the protoplasm of myxomycetes. Plasmodia can be punctured, torn, stretched, droplets pinched off, and fresh surfaces of the peripheral hyaloplasm or the inner granular plasma exposed to the surrounding water, and nineteen times out of twenty the wound is healed.

The same treatment of Amoeba will more often result in loss of proto- 
plasm. The ectoplasm nearly always maintains its identity, but the very dilute endoplasm frequently mixes with the water when it is exposed by a deep rupture. Here is an exception to the general rule stated above, namely, that protoplasm is immiscible in water. There are, however, three important facts to remember in connexion with this uncommon instance of apparently true miscibility of protoplasm : first, the protoplasm which is miscible is exceedingly dilute ; second, the mixing of the liquid endoplasm with water takes place in only about fifty per cent. of the cases; and third, with miscibility the protoplasm as such is lost. The endoplasm of the ciliate infusorium Euplotes, which is the most liquid protoplasm of any examined by me, is also frequently miscible in water. Escaped protoplasm from pollen tubes is another exception to the general rule that protoplasm is immiscible. But here, likewise, the protoplasm is very dilute and mixing takes place in only about half the number of cases.

In examining protoplasm with especial reference to its miscibility in water one must not be misled by the miscibility of an abundance of cell sap, which is not strictly protoplasm and which occupies so large a part of the interior of some plant cells. If one of the large internodal cells of Chara be cut in two the contents will flow out and diffuse rapidly in the surrounding water, but the by far greater portion of this outflowing substance is cell sap. The Chara protoplast consists of two thin layers (the outer quiescent, the inner streaming) of protoplasm lining the cell wall, and the bulk of the cell content is made up of the vacuolar cell sap. It is this cell sap which mixes in the surrounding water, while what little of the protoplasm flows out can be seen as small isolated and immiscible clumps scattered about in the water.

The above experimental facts justify the conclusion that living protoplasm, in the great majority of instances, and in all cases where the living substance is normal and above a minimum viscosity, is immiscible in water.

Whatever our point of view on the water-miscibility of protoplasm, we are forced to admit that in most instances it does not mix with water when exposed to it. The question now arises, Why is protoplasm usually immiscible? Chambers $(9$, p. 2$)$, who holds that protoplasm is miscible in water, answers this question by saying that the condition of miscibility obtains unless a protective membrane or surface layer intervenes. Viewed in this light the problem practically becomes non-existent, because in most instances a membrane does intervene, and when no membrane intervenes we are usually justified, for other reasons than the inability of the protoplasm to form a membrane, in assuming the protoplasm to be degenerate. That the surface layer is in many respects protective may be reasonably assumed, but is not the surface layer protoplasm? It differs, to be sure, physically, and possibly also chemically, from the inner protoplasm, just as the ectoplasm differs from the endoplasm, and the endoplasm on the one side of a cell may differ at any moment from the endoplasm on the other side of a cell. 
There is another method of attack on this problem, namely, by water injection. It is this method which probably gives Chambers his chief evidence of the miscibility of protoplasm. He $(9$, p. 2) says, 'If a drop of water be injected slowly and gradually into the egg by means of the mercury injection method, the water diffuses throughout the cytoplasm, diluting it'. Thus also will a blotter or sponge take up water if it is slowly fed to it. Injected sea-water is, however, not always taken up by the protoplasm. Frequently a droplet of water is held in the ovum for some time. The only miscibility of protoplasm which results is the dilution of a small amount of disorganized protoplasm injured by the injection. Chambers $(9$, p. I 2$)$ attributes the formation of a water droplet to 'mechanical compression caused by the force of the injection', which produces 'a coagulation film about the injected droplet to form a vacuole'. There would thus obtain a condition identical with that of the surface protoplasm of myxomycetes or Amoeba. The membrane of the protoplasm surrounding such an injected water droplet exhibits osmotic properties similar to those of the exterior plasma-membrane, as shown by the experiments of Kite (22, p. 4), who says, 'A small dose of distilled water is taken up by the surrounding cytoplasm of the starfish egg quite slowly. A vacuole of sea-water requires a somewhat longer time to disappear, while a vacuole filled with hypertonic sea-water increases in size.'

Injection of water does not always result in the formation of a water vacuole. If the quantity injected be sufficiently great, most of the protoplasm goes into solution, i. e. is truly miscible. Some of the egg contents may remain undiluted. What have we as a result of such a dilution? It requires but a glance or a tear with a needle to demonstrate the degenerate state of the protoplasm. Normal living protoplasm as such no longer exists.

Dead protoplasm is frequently water-miscible. The degenerate coagulum usually disintegrates, sometimes slowly and sometimes with great rapidity, though it may persist in water for hours. The rate of diffusion may even vary in different regions of the same protoplasmic mass (37, p. $\left.3^{\text {I6 }}\right)$.

Miscibility apparently results from a break-down of organization. Excessive imbibition and consequent swelling of a Fucus ovum before diffusion of the egg contents suggests this. With a break-down of organization, which may be nothing more than a collapse of colloidal structure, the protoplasm is no longer able to resist imbibition pressure, and diffusion results.

Two main factors, then, seem to be responsible for the miscibility of protoplasm, namely, disorganization (in by far the greater number of cases) and extreme liquidity (in some few instances).

A very interesting instance of protoplasm seemingly 'attempting' to 
hold its own against disorganization is the following observed behaviour of the escaped protoplasm of a sea-urchin ovum. I have watched such free protoplasm go through the process of rounding up, which is, when the protoplasm is very viscous, comparatively slow. Usually the process of healing is completed and the escaped droplet of protoplasm maintains its identity. Often, however, the droplet is not quite fully formed, part of its surface remaining momentarily ragged. This exposed, ragged protoplasm, without any apparent membrane, remains, until the turning-point in the process is reached, quite immiscible in the water with which it is in contact. One can almost imagine the protoplasm 'struggling' to retain itself. If it succeeds, the droplet is formed. If it fails, miscibility results, as a consequence of disorganization.

To deny the water-miscibility of a hydrosol forces one to explain an apparent incongruity. But one must bear in mind that protoplasm is not a simple emulsion of two phases such as milk, but is exceedingly complex, possessing an intricate colloidal structure and a still more intricate and as yet unfathomable organization.

MacDougal (25, p. 60I) has suggested that solubility of protoplasm may depend 'upon differences in the carbohydrate component', i.e. ' living matter in which the pentosan was a mucilage like gum arabic would be miscible with water, while a pentosan like tragacanth would be less soluble, and a group like agar, for example, would not appear to be soluble at all'. Solubility 'might also result from the character of the aminocompounds or proteins present, especially in a protoplasm rich in nitrogen'. This does not, it seems to me, explain the true state of affairs. It is probably structure primarily which keeps protoplasm from losing its identity as living substance by mixing in the surrounding water. I do not mean to imply that structure alone is the deciding factor, for chemical changes may conceivably play at least a minor part. For example, oil, through the activity of an enzyme, may be split into glycerine and an acid and thus become soluble in water. But the emphasis in the case of protoplasm should, I think, be placed upon structure rather than upon chemical composition. ${ }^{1}$

Gaidukov (16, p. 16I) says that 'protoplasm can only be a hydrosol if it is covered by a protective wall (plasma-membrane)'. It is, I grant, difficult to conceive of a hydrosol being immiscible in water unless a membrane intervenes. That a membrane does usually intervene is true, but it is itself protoplasm and as such gives no evidence, even when liquid, of miscibility. The membrane is apparently not the cause but a result of

1 It is possible that the large size of the molecules of the components of protoplasm is a factor in preventing miscibility. The diffusion rate of a solute varies directly as the molecular energy (or the absolute temperature) and inversely as the viscosity of the liquid and dimensions of the particles (28, p. 105). The protein molecules which make up a large part of protoplasm are among the largest known, consequently they diffuse very slowly. 


\section{Seifriz.-Observations on some Physical Properties of}

immiscibility of the protoplasm. Perhaps it is only the true sol state of protoplasm (the endoplasm of $A$ moeba, e.g.) which is sometimes watermiscible, and only when the liquid endoplasm rapidly attains a higher viscosity at its exposed surface does it save itself from destruction. This hypothesis would demand a gel state of protoplasm even when the living substance is of quite low viscosity. Whatever our point of view we have the experimental fact that living, normal protoplasm does not mix with water, unless extremely dilute, and even then it does so in only half the cases observed. ${ }^{1}$

The affirmation of the miscibility of protoplasm in water robs, it seems to me, the living substance of all organization, robs it of its innate power to maintain its individuality, and makes of this highly complex colloid a comparatively simple aqueous dispersion which can be mixed in water with no change other than a dilution. In view, then, of these facts, how are we to interpret the taking up of water by protoplasm?

The taking up of water by protoplasm is, in my opinion, essentially an imbibition process. The colloidal constitution of protoplasm is responsible for the absorption and retention of water by the living substance.

\section{SUMMARY.}

I. Protoplasm when subjected to dissection in water is, in by far the greater number of instances, immiscible in the surrounding medium.

2. When the condition of water-miscibility of protoplasm does occur, it is ascribable to one of two factors-extreme liquidity or disorganization (i. e. death).

3. The immiscibility of protoplasm is possibly due to the characteristic colloidal nature of the living substance, which may be merely colloidal structure, although chemical constitution is probably also a controlling factor.

4. The absorption and retention of water by protoplasm is essentially an imbibition process.

\section{BIBLIOGRAPHY.}

1 Arthur, J. C. : Movement of Protoplasm in Coenocytic Hyphae. Ann. Bot., vol. xi, pp. $49^{\mathrm{I}-507, \mathrm{I} 897}$.

2. BARber, M. A.: The Pipette Method in the Isolation of Single Micro-organisms and in the Inoculation of Substances into Living Cells. Philippine Jour. Sci., Sec. B., vol. ix, pp. 307-60, I914.

3. BARy, H. A. DE: Die Mycetozoen. Leipzig, I864.

1 In connexion with the problem of protoplasmic miscibility it is interesting to consider the protrusion of 'naked' protoplasm through clefts and pores in diatoms. It is difficult to conceive of such an external stream of protoplasm, by means of which diatoms are supposed to move (33, p. I I8), as water-miscible. 
4. BechHold, H. : Colloids in Biology and Medicine. New York, I9I9.

5. Berczel.ter, L. : Zur physikalischen Chemie der Zellmembranen. Biochem. Zeitschr., vol. lxxxiv, pp. 59-74, I9I 7 .

6. Burton, E. F. : The Physical Properties of Colloidal Solutions. London, I9I6.

7. Bütschli, O. : Meine Ansicht über die Struktur des Protoplasmas und einige ihrer Kritiker. Arch. Entw.-mech. Org., vol. xi, pp. 499-584, I90I.

8. Chambers, R. : Microdissection Studies on the Physical Properties of Protoplasm. Lancet Clinic, I-8, Cincinnati, Mar. 27, I9I5.

9. : Microdissection Studies. I. The Visible Structure of Cell Protoplasm and Death Changes. Amer. Jour. Physiol., vol. xliii, pp. I-I 2, I9I 7 .

10. : The Microvivisection Method. Biol. Bull., vol. iv, pp. I I I-36, I9I8.

11. : A Report on Results obtained from the Microdissection of Certain Cells. Trans. Royal Soc. Canada, vol. xii, sec. 4, pp. 4I-6, I9I8.

12. Czapek, F.: Chemical Phenomena in Life. London, igi I.

13. Dewar, J.: Soap Bubbles of Long Duration. Roy. Inst. Great Britain, 1-34, Jan. 19, I9I 7.

14. Dujardin, F. : Recherches sur les Organismes inférieurs. Zoologie, vol. iv, $\mathbf{2}^{\circ}$ série, pp. $343^{-}$ 76,1835 .

15. Fischer, M. H. : Oedema and Nephritis. New York, I9I5.

16. Gaidukov, N.: Dunkelfeldbeleuchtung und Ultramikroskopie in der Biologie und in der Medizin. Jena, I910.

17. Harper, R. A.: The Structure of Protoplasm. Amer. Jour. Bot., vol. vi, pp. 273-300, igig.

18. Harvey, E. N.: Is the Fertilization Membrane of Arbacia Eggs a Precipitation Membrane? Biol. Bull., vol. xxvii, pp. 237-9, I914.

19. Hertwig, O.: Die Zelle und die Gewebe. Jena, I 893.

20. Höвer, R. : Physikalische Chemie der Zelle und der Gewebe. Leipzig, I9I4.

21. Hyman, L. H.: Metabolic Gradients in Amoeba and their Relation to the Mechanism of Amoeboid Movement. Jour. Exp. Zool., vol. xxiv, pp. 55-99, I9I7.

22. Kite, G. L. : The Relative Permeability of the Surface and Interior Portion of the Cytoplasm of Animal and Plant Cells. Biol. Bull., vol. xxv, pp. I-7, I9r3.

23. : Studies on the Permeability of the Internal Cytoplasm of Animal and Plant Cells. Amer. Jour. Physiol., vol. xxxvii, pp. 282-99, I9I 5 .

24. Lehmann, O.: Künstliche Zellen mit flüssig-kristallinischen Wänden. Verhand. Deut. Phys. Gesell., vol. x, pp. 406-9, I908.

25. MacDougal, D. T. : Growth in Organisms. Sci., vol. xlix, pp. 599-605, I I I 9.

26. МонL, H. von : Ueber den Bau des Chlorophylls. Bot. Zeit., vol. xiii, pp. 89-99, 1855 .

27. Mottier, D. M. : Beiträge zur Kenntniss der Kerntheilung in den Pollenmutterzellen einiger Dikotylen und Monokotylen. Jahrb. wiss. Bot., vol. xxx, pp. 169-204, 1897.

28. Perrin, J. : Les Atomes (Die Atome), tr. Lottermoser. Dresden, I9I 4.

29. PfeffFer, W.: Osmotische Untersuchungen. Leipzig, 1877.

30. — Zur Kenntniss der Plasmahaut und der Vacuolen. Abh. König. Sächs. Gesell. Wiss., Math.-Phys. Cl., vol. xvi, pp. I85-344, I890-I.

31. : Physiology of Plants, tr. Ewart, I 900.

32. Prenant, A., Bouin, P., et Millard, L.: Traité d'Histologie. Paris, 1904.

33. Pringsheim, E. G.: Die Reizbewegungen der Pflanzen. Berlin, 19i 2.

34. Quincke, G. : Ueber periodische Ausbreitung an Flüssigkeitsoberflächen und dadurch hervorgerufene Bewegungserscheinungen. Ann. der Phys. und Chem., vol. xxxv, pp. 580-642, 1888.

35. - : Über unsichtbare Flüssigkeitsschichten und die Oberflächenspannung fluissiger Niederschläge bei Niederschlagmembranen, Zellen, Colloiden und Gallerten. Ann. der Phys., vol. vii, pp. 631-82, 1902.

36. $:$ Idem. Ibid., pp. 70I-44, I902.

37. SeIfriz, W. : Observations on the Structure of Protoplasm by Aid of Microdissection. Biol. Bull., vol. xxxiv, pp. 307-24, I9I8.

38. : Viscosity Values of Protoplasm as determined by the Aid of Microdissection. Bot. Gaz., vol. 1xx, 1920.

39. Stempell, W.: Über die Funktion der pulsierenden Vacuolen und einen Apparat zur Demonstration derselben. Zool. Jahrb., Abt. Zool. und Physiol., vol. xxxiv, Pp. 437-78, 1914. 


\section{Seifriz-O-Observations on some Properties of Protoplasm.}

40. Stiles, W., and Jorgensen, I. : Studies in Permeability. IV. The Action of Various Organic Substances on the Permeability of the Plant Cell, and its bearing on Czapek's Theory of the Plasma Membrane. Ann. Bot., vol. xxxi, pp. 47-76, I9I 7 .

41. - Quantitative Measurement of Permeability. Bot. Gaz., vol. lxv, pp. 526-34, I9I8.

42. Taylor, C. V.: Demonstration of the Function of the Neuromotor Apparatus in Euplotes by the Method of Microdissection. Univ. Cal. Pubs., 1920.

43. TAylor, W. W.: The Chemistry of Colloids. London, I9 5 .

44. Vonwiller, P.: Über den Bau des Plasmas der niedersten Tiere. Arch. Protistenk., vol. xxxviii, pp. 279-323, I9I8.

45. Wrześniowski, A.: A Note on the Contractile Vacuole of Infusoria. (Russian) Pub. St. Petersburg Dept. Zool., I6I-8, I869.

46. pp. $25-48,1869$.

47. Yamanouchi, S. : The Life-History of Polysiphonia Violacea. Bot. Gaz., vol. xli, pp. 425-33, I906. 


\section{$2 \mathrm{BHL}$ Biodiversity Heritage Library}

Seifriz, William. 1921. "Observations on some physical properties of protoplasm by aid of microdissection." Annals of botany 35, 269-296. https://doi.org/10.1093/oxfordjournals.aob.a089757.

View This Item Online: https://www.biodiversitylibrary.org/item/235780

DOI: https://doi.org/10.1093/oxfordjournals.aob.a089757

Permalink: https://www.biodiversitylibrary.org/partpdf/319002

\section{Holding Institution}

Smithsonian Libraries

\section{Sponsored by}

Biodiversity Heritage Library

\section{Copyright \& Reuse}

Copyright Status: Not in copyright. The BHL knows of no copyright restrictions on this item.

This document was created from content at the Biodiversity Heritage Library, the world's largest open access digital library for biodiversity literature and archives. Visit BHL at https://www.biodiversitylibrary.org. 